\title{
Efficacy of Calcium Channel Blocker in the Secondary Prevention of Myocardial Infarction Retrospective Analysis of the 10-Year Prognosis of Coronary Thrombolysis-Treated Patients
}

\author{
Shigemasa Tani, MD; Ikuyoshi Watanabe, MD; Ken Nagao, MD*; Kimio Kikushima, MD; \\ Kazuhiro Watanabe, MD; Takeo Anazawa, MD; Hirofumi Kawamata, MD; \\ Eizo Tachibana, MD; Shingo Furuya, MD; Toshifumi Sasanuma, MD; \\ Toshio Kushiro, MD; Katsuo Kanmatsuse, MD
}

\begin{abstract}
Background Calcium channel blockers (CCBs) may have a positive influence on the long-term prognosis of Japanese patients with ischemic heart disease.

Methods and Results The effect of nifedipine-retard (NR) $(n=202)$ compared with that of non-CCB treatment $(n=92)$ on the secondary prevention of myocardial infarction (MI) was retrospectively investigated in patients who had survived acute MI between 1987 and 1996. The primary endpoint was the occurrence of cardiac death or non-fatal MI. The median follow-up was $6.3 \pm 2.4$ years. The incidence of cardiac events was $8.9 \%$ in the NR group and $14.1 \%$ in the non-CCBs group ( $\mathrm{p}=0.14$, odds ratio (OR): $0.584,95 \%$ confidence interval $(\mathrm{CI})$ : $0.286-$ $1,193)$. However, subanalysis revealed that NR significantly reduced the incidence of cardiac events in patients aged less than 55 years $(4.2$ vs $18.2 \%, \mathrm{p}=0.016$, OR: 0.180 , 95\%CI: $0.045-0.721)$ and those who did not smoke (8.6 vs $16.4 \%$, $\mathrm{p}=0.048$, OR: 0.462 , $95 \%$ CI: $0.203-0.999$ ).

Conclusion Although this was a retrospective analysis, it showed that NR did not cause an increase in the incidence of cardiac events in post-MI patients; it even prevented cardiac events, especially in those who were less than 55 years of age and in non-smokers, suggesting the potential usefulness of CCBs in the secondary prevention of MI in Japan. (Circ J 2004; 68: 853-859)
\end{abstract}

Key Words: Calcium channel blocker; Long-term prognosis; Myocardial infarction (MI); Nifedipine-retard; Secondary prevention

$\mathbf{E}$ ver since the results of the SPRINT study were reported in 1988, the role of calcium-channel blockers (CCBs) in the secondary prevention of myocardial infarction (MI) has been viewed rather negatively. Not only was any beneficial effect on the development of cardiac events denied, but these drugs were even considered to cause an increase in cardiac events? 2,3 Subsequent meta-analyses could not demonstrate their efficacy, 45 However, Furberg et al evaluated only short-acting nifedipine, and the controversy was finally resolved because it was very high doses of this drug only that were associated with an increase in cardiac events? Finally, in $1997 \mathrm{WHO} / \mathrm{ISH}$ issued a statement that the benefits and risks of treatment with CCBs had not been confirmed, but that there was no evidence of their harmfulness?

The prominent characteristic of ischemic heart disease (IHD), particularly MI, in Japanese patients is that coronary

(Received January 8, 2004; revised manuscript received June 7, 2004; accepted July 2, 2004)

Division of Cardiology, Department of Internal Medicine, Nihon University School of Medicine and Surugadai Nihon University Hospital, *Department of Emergency and Critical Care Medicine, Nihon University School of Medicine, Tokyo, Japan

Mailing address: Shigemasa Tani, MD, Department of Cardiology, Surugadai Nihon University Hospital, 1-8-13 Kanda-Surugadai, Chiyoda-ku, Tokyo 101-8309, Japan. E-mail: tanishigem@yahoo.co. jp vasospasm is much more involved as the underlying mechanism than is the case in Westerners ${ }^{8-10}$ It is also noted that fewer Japanese cases demonstrate multivessel disease, ${ }^{11,12}$ and there are more cases with relatively good cardiac function and a better prognosis ${ }^{13}$ Because the underlying pathology of IHD is clearly different in Japanese and Westerners, it is quite possible that the response to CCBs in Japanese also differs from that in Westerners.

To clarify these issues, we retrospectively studied the effects of sustained-release nifedipine (nifedipine-retard (NR)) on the 10-year, long-term prognosis of coronarythrombolysis-treated patients with acute MI.

\section{Methods}

Subjects

The present study included 294 patients who could be followed up, out of a total of 297 patients who had been admitted to the emergency department from 1985 to 1996 with a first event of acute MI, and who were discharged alive after receiving coronary thrombolysis treatment (follow-up rate: $99.0 \%$ ).

NR was a slow-release formulation of short-acting nifedipine (t1/2: $1.7 \pm 0.4 \mathrm{~h}$; Cmax: $117 \pm 15 \mathrm{ng} / \mathrm{ml})$ with $\mathrm{t} 1 / 2$ : $3.2 \pm 0.6 \mathrm{~h}$ and Cmax: $26 \pm 10 \mathrm{ng} / \mathrm{ml}{ }^{14,15}$ Most of the patients received $40 \mathrm{mg} /$ day divided into twice daily doses.

The diagnosis of acute MI was based on the following 
Table 1 Clinical Characteristics of the 2 Study Groups

\begin{tabular}{|c|c|c|c|}
\hline & $\begin{array}{l}\text { Nifedipine-retard } \\
\quad n=202\end{array}$ & $\begin{array}{l}\text { Non-calcium channel blockers } \\
\qquad n=92\end{array}$ & $p$ value \\
\hline \multicolumn{4}{|l|}{ General } \\
\hline Age (years) & $58 \pm 10$ & $59 \pm 11$ & 0.35 \\
\hline Male (\%) & 82 & 92 & 0.02 \\
\hline$B M I\left(\mathrm{~kg} / \mathrm{m}^{2}\right)$ & $24 \pm 3.5$ & $24 \pm 3.3$ & 0.83 \\
\hline \multicolumn{4}{|l|}{ Cardiovascular status } \\
\hline Infarct-related artery LAD (\%) & 56 & 61 & 0.27 \\
\hline Successful reperfusion (\%) & 90 & 87 & 0.43 \\
\hline Good collateral vessels (\%) & 16 & 23 & 0.88 \\
\hline No. of diseased vessel (1/2/3) (\%) & $77 / 18 / 5$ & 74/17/9 & 0.80 \\
\hline Peak CK $(I U / L)$ & $3,460 \pm 2,500$ & $3,548 \pm 2,549$ & 0.78 \\
\hline $\operatorname{LVEF}(\%)$ & $56 \pm 13$ & $55 \pm 13$ & 0.68 \\
\hline $\operatorname{LVEDVI}\left(\mathrm{ml} / \mathrm{m}^{2}\right)$ & $99 \pm 13$ & $95 \pm 29$ & 0.44 \\
\hline Swan-Forrester class I (\%) & 78 & 70 & 0.30 \\
\hline Killip class I $(\%)$ & 89 & 83 & 0.26 \\
\hline Total cholesterol $(\mathrm{mg} / \mathrm{dl})$ & $209 \pm 46$ & $207 \pm 39$ & 0.79 \\
\hline LDL-cholesterol $(\mathrm{mg} / \mathrm{dl})$ & $141 \pm 39$ & $138 \pm 40$ & 0.67 \\
\hline HDL-cholesterol $(\mathrm{mg} / \mathrm{dl})$ & $40 \pm 9.3$ & $39 \pm 9.6$ & 0.73 \\
\hline Triglyceride $(\mathrm{mg} / \mathrm{dl})$ & $164 \pm 134$ & $151 \pm 82$ & 0.49 \\
\hline Uric acid $(\mathrm{mg} / \mathrm{dl})$ & $5.9 \pm 1.8$ & $5.8 \pm 1.6$ & 0.88 \\
\hline \multicolumn{4}{|l|}{ Risk factors } \\
\hline Systemic hypertension (\%) & 60 & 34 & $<0.0001$ \\
\hline Diabetes mellitus (\%) & 29 & 23 & 0.27 \\
\hline Hypercholesterolemia (\%) & 72 & 66 & 0.30 \\
\hline Smoker $(\%)$ & 80 & 82 & 0.72 \\
\hline \multicolumn{4}{|l|}{ Medications } \\
\hline Aspirin (\%) & 82 & 77 & 0.31 \\
\hline ACE inhibitor (\%) & 25 & 17 & 0.17 \\
\hline$\beta$-blocker $(\%)$ & 21 & 18 & 0.63 \\
\hline Nitrate $(\%)$ & 78 & 67 & 0.06 \\
\hline Lipid lowering agent (\%) & 71 & 61 & 0.13 \\
\hline Diuretics (\%) & 10 & 14 & 0.19 \\
\hline Digitalis (\%) & 11 & 14 & 0.29 \\
\hline \multicolumn{4}{|l|}{ Mean blood pressure } \\
\hline Systolic $(\mathrm{mmHg})$ & $133 \pm 14$ & $128 \pm 16$ & 0.02 \\
\hline Diastolic ( $m m H g)$ & $79 \pm 8$ & $79 \pm 9$ & 0.76 \\
\hline Post-MI angina (\%) & 4.5 & 5.4 & 0.89 \\
\hline NYHA I/II/IIII/IV (\%) & $83 / 15 / 2 / 0$ & $84 / 14 / 2 / 0$ & 0.96 \\
\hline
\end{tabular}

$B M I$, body mass index; CK, creatine kinase; LVEF, left ventricular ejection fraction; LVEDVI, left ventricular end-diastolic volume index; ACE, angiotensin-converting enzyme; NYHA, New York Heart Association; LAD, left anterior descending artery; LDL, low density lipoprotein; $H D L$, high density lipoprotein.

criteria: continuous symptoms of acute MI and any of the following signs on the 12-lead ECG: ST-segment elevation of at least $0.1 \mathrm{mV}$ in 2 or more limb leads, ST-segment elevation of at least $0.2 \mathrm{mV}$ in the precordial leads, or left bundle branch block that lasted longer than $30 \mathrm{~min}$.

\section{Coronary Reperfusion Therapy}

Thrombolytic therapy was performed as the first choice of reperfusion treatment of acute MI if there were no contraindications. Urokinase was the main drug used for thrombolytic therapy until 1990, but since 1992 it has been pro-urokinase, tissue-plasminogen activator (tPA) or mutant tPA. If TIMI grade 3 flow $^{16}$ was not observed in the infarctrelated artery, rescue angioplasty was immediately performed.

Patients with any of the following contraindications were excluded from thrombolytic therapy: more than $6 \mathrm{~h}$ since the onset of acute MI, age over 75 years, history of stroke or central nervous system damage, left main coronary artery disease, active bleeding or a bleeding tendency, recent trauma or major surgery, and a systolic blood pressure greater than $180 \mathrm{mmHg}$ or a diastolic blood pressure greater than $110 \mathrm{mmHg}$, as measured in the emergency room.

All patients gave written informed consent before under- going thrombolytic therapy.

Data Collection

The initial prospective data were collected from the coronary reperfusion therapy database and medical records of the hospital.

A diagnosis of diabetes was made when hemoglobinA1c was $5.5 \%$ or above, and that of hypercholesterolemia when the total cholesterol concentration was $220 \mathrm{mg} / \mathrm{dl}$ or above. The blood pressure was the mean of 3 measurements taken while the patient was hospitalized, excluding during the acute phase of MI. Reperfusion of the infarct-related artery was considered successful if TIMI grade 3 flow was achieved, whereas Cohns grade 3 signified good development of collateral vessels. Each coronary lesion that resulted in more than a 50\% reduction in luminal diameter was considered clinically significant. Left ventricular ejection fraction and left ventricular end-diastolic volume index were calculated from the left ventriculography findings at 4 weeks after the onset of acute MI.

\section{Follow-up and Primary Endpoints}

If NR therapy was discontinued or exchanged for another drug, that point was the end of the surveillance period 
for that subject; similarly the point when a CCB was coadministered to a subject in the non-CCB group became the end of the surveillance period for that subject.

The primary endpoints of this study included recurrent MI (fatal and non-fatal), sudden cardiac death, and death because of congestive heart failure. The diagnosis of recurrent MI was based on the same criteria as those used for initial inclusion in the study. The diagnosis of sudden cardiac death was based on Braunwald's definition; 17 namely, the patient exhibited one or more symptoms suddenly and unexpectedly, and then died within an hour of onset. In cases of drug-resistant post-infarction angina pectoris or restenosis of the site of revascularization diagnosed during the chronic phase of MI, either percutaneous coronary angioplasty or coronary bypass surgery was performed.

\section{Statistical Analysis}

Continuous values were expressed as the mean \pm standard deviation (SD) and were compared between the groups by Student's t-test. The chi-squared test was used to compare the frequency of each categorical variables. The odds ratio (OR) with $95 \%$ confidence interval (CI) was used to analyze the significant differences in the incidence of cardiac events. The significance of the incidence of cardiac events over time was evaluated in accordance with the logrank test by obtaining an event-free ratio using the KaplanMeier estimation methods. Because this study was retrospective, differences in the patient characteristics between the groups were unavoidable. To exclude the influence of these differences, the participants were divided into subgroups and each subgroup was then further classified based on the incidence of cardiac events. The NR group and the non-CCBs group were compared 18 A $\mathrm{p}$-value less than 0.05 was considered statistically significant.

\section{Results}

\section{Baseline Characteristics of the Patients and the Prescribed Calcium Channel Blockers}

There were 294 patients (250 male, 44 female; age 58土 10 years) who were treated with either NR $(n=202)$ or nonCCBs $(n=92)$ and the median follow-up was $6.3 \pm 2.4$ years. The baseline characteristics are shown in Table 1. There were significant differences in the ratio of males, past history of systemic hypertension, and systolic blood pressure, but no significant differences in age, BMI, cardiovascular status, blood lipid and uric acid levels, other coronary risk factors, post MI angina, New York Heart Association class, or medications.

At the time of discharge, CCBs were prescribed in 250 cases: NR (220 cases), nisoldipine (10 cases), longacting diltiazem (5 cases), short-acting diltiazem (4 cases),

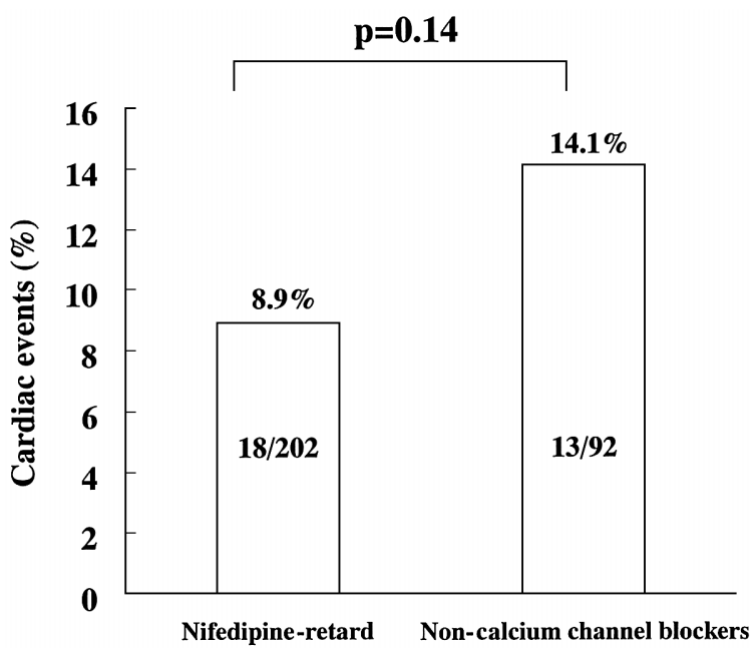

Fig 1. Effect of nifedipine-retard on the incidence of cardiac events.

long-acting nicaldipine (5 cases), short-acting nicardipine ( 3 cases), and short-acting nifedipine (3 cases). During the study period, 202 of the 220 patients continued to take the prescribed NR and the other 18 patients, who discontinued it because of adverse effects such as headache, hot flushes, and palpitations, were excluded from the study.

\section{Cardiac Events}

As shown in Fig 1 and Table 2, cardiac events occurred in a total of 18 of the 202 patients in the NR group (8.9\%) and in 13 of the 92 patients in the non-CCBs group $(14.1 \%)$, indicating a 1.58 -fold lower risk in the former, although the difference was not significant $(\mathrm{p}=0.14$.) The incidence of recurrent MI for NR vs non-CCBs was $5.9 \%$ vs $7.9 \%(\mathrm{p}=0.59), 1.0 \%$ vs $4.3 \%(\mathrm{p}=0.06)$ for death from congestive heart failure and $2.0 \%$ vs $2.2 \%(\mathrm{p}=0.91)$ for sudden cardiac death. The OR for all cardiac events in the NR group as compared with the non-CCBs was 0.584 $(\mathrm{p}=0.14,95 \% \mathrm{CI}, 0.286-1.193)$. The Kaplan-Meier estimates of the free rate of cardiac events at 10 years were $84.7 \%$ in the NR group and $78.0 \%$ in the non-CCBs group, showing no significant differences between the 2 groups (Fig 2). Coronary bypass surgery was performed in 16 patients $(7.9 \%)$ in the NR group and in 5 patients $(5.4 \%)$ in the non-CCB group $(\mathrm{p}=0.44)$. Percutaneous coronary intervention was performed in 57 patients in the NR group $(28.2 \%)$ and in 21 patients $(22.8 \%)$ in the non-CCB group $(\mathrm{p}=0.46)$.

\section{Subgroup Analysis}

Because there were significant differences in the base-

Table 2 Incidence of Cardiac Events in the 2 Study Groups

\begin{tabular}{lccc}
\hline \hline & $\begin{array}{c}\text { Nifedipine-retard } \\
n=202\end{array}$ & $\begin{array}{c}\text { Non-calcium channel blockers } \\
n=92\end{array}$ & $p$ value \\
\hline Cardiac events & & & \\
Recurrent myocardial infarction (\%) & $12(5.9)$ & $7(7.9)$ & 0.59 \\
Death from heart failure (\%) & $2(1.0)$ & $4(4.3)$ & 0.06 \\
Sudden cardiac death (\%) & $4(2.0)$ & $2(2.2)$ & 0.91 \\
Overall (\%) & $18(8.9)$ & $13(14.1)$ & \\
& $p=0.140$, OR $0.584,95 \%$ CI $0.286-1.193$. & \\
\hline
\end{tabular}

OR, odds ratio; CI, confidence interval. 
(\%)

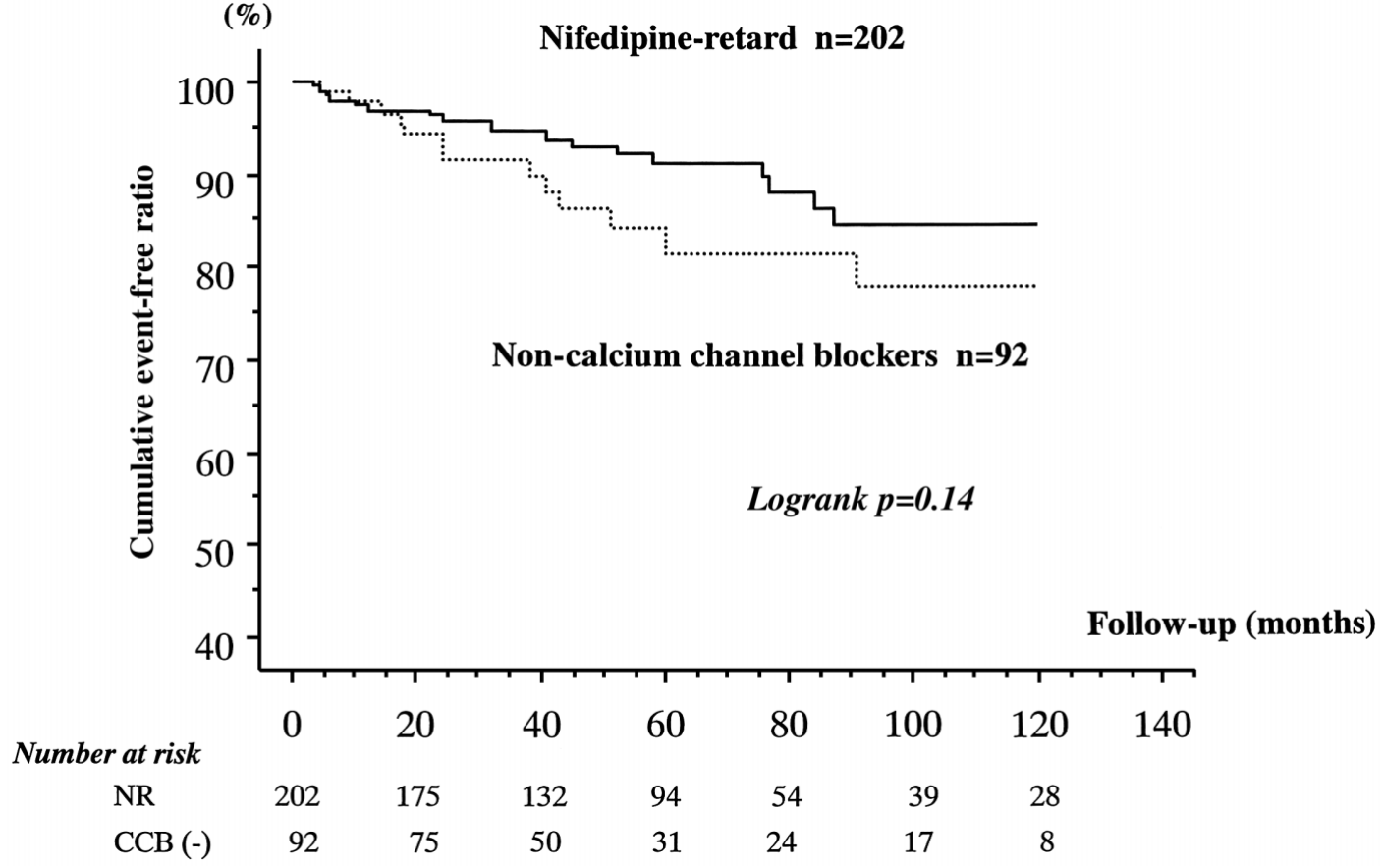

Fig 2. Event-free curve showing the incidence of cardiac events in the study groups.

Table 3 Subclass Analysis of the 2 Study Groups

\begin{tabular}{|c|c|c|c|c|c|c|c|c|c|}
\hline & \multicolumn{3}{|c|}{ Nifedipine-retard } & \multicolumn{3}{|c|}{ "Non-calcium channel blockers } & \multirow{2}{*}{$p$ value } & \multirow{2}{*}{ Odds ratio } & \multirow{2}{*}{$95 \% C I$} \\
\hline & Total & Cardiac events & $(\%)$ & Total & Cardiac events & $(\%)$ & & & \\
\hline \multicolumn{10}{|l|}{$\operatorname{Sex}$} \\
\hline Male & 165 & 14 & 8.5 & 85 & 13 & 15.3 & 0.072 & 0.500 & $0.235-1.064$ \\
\hline \multicolumn{10}{|l|}{ Age (years) } \\
\hline$<55$ & 71 & 3 & 4.2 & 33 & 6 & 18.2 & 0.016 & 0.180 & $0.045-0.721$ \\
\hline $55-64$ & 69 & 8 & 11.6 & 30 & 2 & 6.7 & 0.381 & 2.007 & $0.422-9.534$ \\
\hline$\geq 65$ & 58 & 6 & 10.3 & 29 & 5 & 17.2 & 0.490 & 0.658 & $0.200-2.160$ \\
\hline \multicolumn{10}{|l|}{ Hypertension } \\
\hline Yes & 117 & 11 & 9.4 & 31 & 5 & 16.1 & 0.243 & 0.532 & $0.184-1.535$ \\
\hline No & 85 & 7 & 8.2 & 61 & 8 & 13.1 & 0.265 & 0.561 & $0.203-1.590$ \\
\hline \multicolumn{10}{|c|}{ Diabetes mellitus } \\
\hline Yes & 58 & 5 & 8.6 & 21 & 3 & 14.3 & 0.241 & 0.422 & $0.100-1.788$ \\
\hline No & 144 & 13 & 9.0 & 71 & 10 & 14.1 & 0.273 & 0.630 & $0.276-1.439$ \\
\hline \multicolumn{10}{|c|}{ Total cholesterol } \\
\hline$<220 \mathrm{mg} / \mathrm{dl}$ & 55 & 5 & 9.1 & 20 & 1 & 5.0 & 0.602 & 1.773 & $0.207-15.202$ \\
\hline$\geq 220 \mathrm{mg} / \mathrm{dl}$ & 95 & 8 & 8.4 & 44 & 7 & 15.9 & 0.179 & 0.498 & $0.180-1.377$ \\
\hline \multicolumn{10}{|c|}{ Smoking habit at the onset of AMI } \\
\hline Yes & 170 & 16 & 9.4 & 80 & 11 & 13.8 & 0.201 & 0.606 & $0.281-1.307$ \\
\hline No & 32 & 2 & 6.3 & 12 & 2 & 16.7 & 0.697 & 0.645 & $0.059-2.986$ \\
\hline \multicolumn{10}{|c|}{ Quit or never smoked } \\
\hline Yes & 139 & 12 & 8.6 & 67 & 11 & 16.4 & 0.048 & 0.462 & $0.203-0.999$ \\
\hline No & 24 & 4 & 16.7 & 4 & 1 & 25.0 & 0.697 & 0.645 & $0.071-5.871$ \\
\hline \multicolumn{10}{|c|}{ Ejection fraction (\%) } \\
\hline$<50$ & 36 & 4 & 11.1 & 15 & 2 & 13.3 & 0.630 & 0.658 & $0.119-3.624$ \\
\hline$\geq 50$ & 77 & 9 & 11.7 & 36 & 3 & 11.5 & 0.947 & 1.045 & $0.283-3.867$ \\
\hline \multicolumn{10}{|l|}{ Killip class } \\
\hline$I$ & 177 & 15 & 8.5 & 76 & 9 & 11.8 & 0.386 & 0.693 & $0.303-1.586$ \\
\hline II, III, IV & 25 & 3 & 12.0 & 16 & 4 & 25.0 & 0.151 & 0.331 & $0.073-1.498$ \\
\hline \multicolumn{10}{|c|}{ Infarct-related artery } \\
\hline$L A D$ & 112 & 8 & 7.1 & 56 & 9 & 16.1 & 0.071 & 0.416 & $0.160-1.079$ \\
\hline$R C A / L C X$ & 90 & 10 & 11.1 & 36 & 4 & 11.1 & 0.875 & 0.911 & $0.285-2.910$ \\
\hline \multicolumn{10}{|c|}{ No. of diseased vessels } \\
\hline 1 & 130 & 6 & 4.6 & 58 & 5 & 8.6 & 0.243 & 0.493 & $0.150-1.617$ \\
\hline 2 or 3 & 72 & 12 & 16.7 & 34 & 8 & 23.5 & 0.443 & 0.703 & $0.286-1.728$ \\
\hline \multicolumn{10}{|l|}{$\beta$-blocker use } \\
\hline Yes & 42 & 3 & 7.1 & 17 & 1 & 5.9 & 0.873 & 1.203 & $0.125-11.572$ \\
\hline No & 160 & 15 & 9.4 & 75 & 12 & 16 & 0.110 & 0.538 & $0.251-1.150$ \\
\hline
\end{tabular}

$R C A$, right coronary artery; $L C X$, left circumflex artery. 


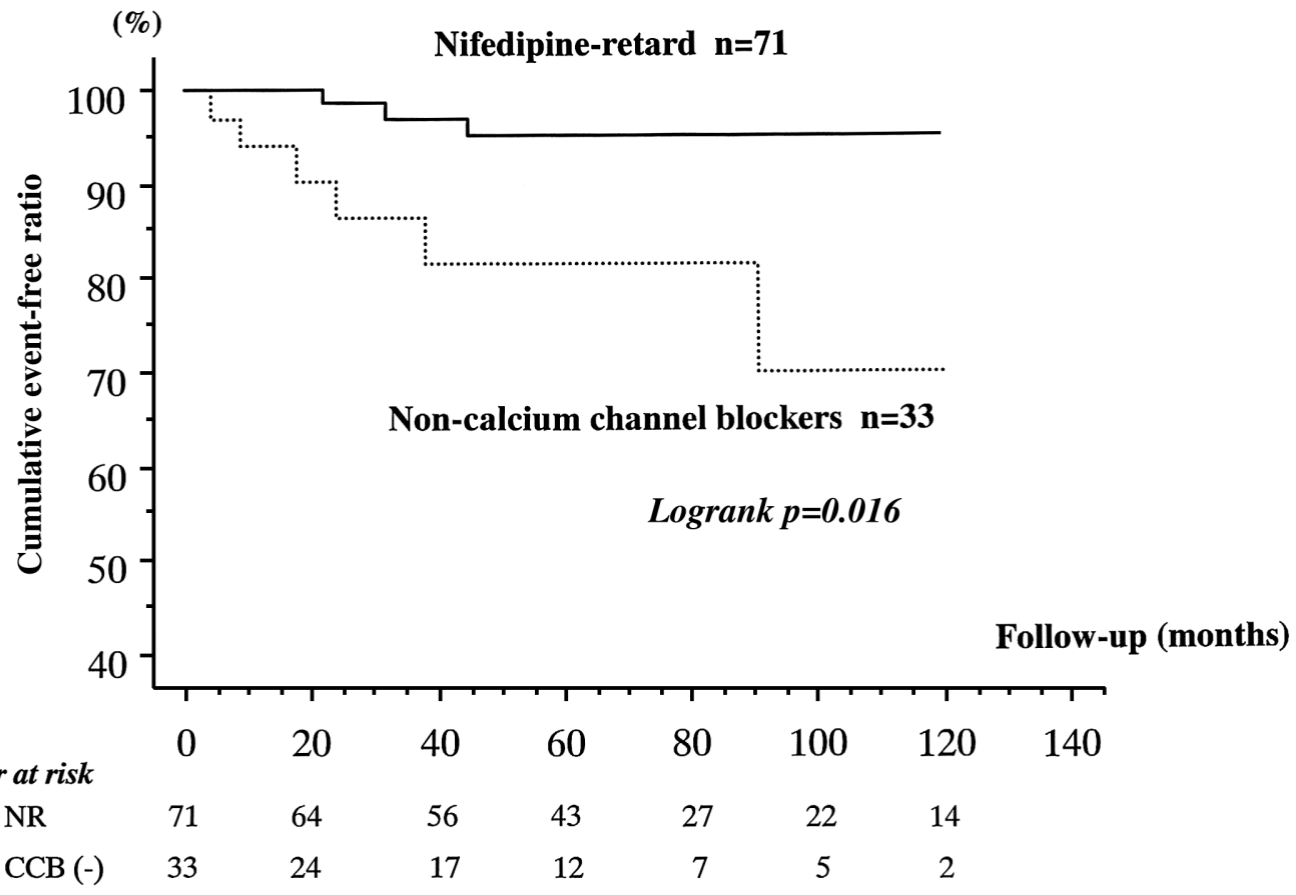

Fig 3. Event-free curve showing the incidence of cardiac events in patients aged less than 55 years.

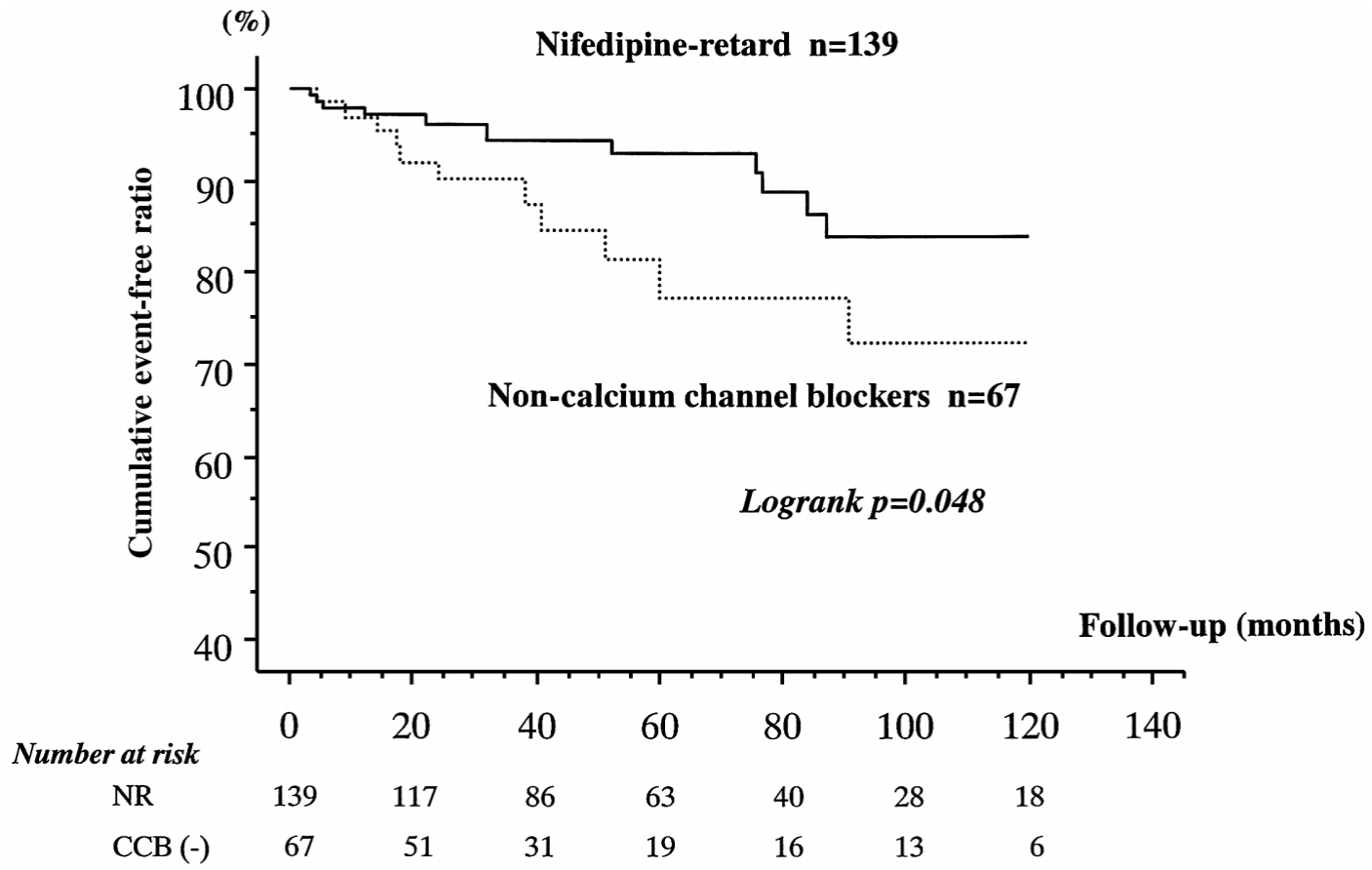

Fig 4. Event-free curve showing the incidence of cardiac events in non-smoking patients.

line characteristics of the ratio of males, the history of systemic hypertension and systolic blood pressure between the 2 groups, as shown in Table 1, the patients were divided into 2 groups to eliminate the influence of the differences on the comparison of the incidence of cardiac events (Table 3 ).

In patients aged under 55 years (mean 47 years), the incidence of cardiac events in the NR group was significantly lower than in the non-CCBs group (4.2 vs $18.2 \%, \mathrm{p}=0.016$ ). An event-free curve derived by the Kaplan-Meier method revealed that the NR group experienced significantly fewer cardiac events than the non-CCBs group (Fig 3). The OR for cardiac events in the NR group as compared with the non-CCBs was 0.180 (95\%CI: 0.045-0.721).

In patients who smoked continuously during the study period, there were no differences in the incidence of cardiac events between the 2 groups, but a significant decrease in the incidence of cardiac events was observed in nonsmoking patients ( 8.6 vs $16.4 \%, \mathrm{p}=0.048$ ). Kaplan-Meier analysis revealed that the NR group experienced significantly fewer cardiac events than the non-CCBs group 
(Fig 4). The OR was 0.462 (95\%CI: 0.203-0.999). In cases under 55 years and for non-smokers, there were no differences in the patient background factors between the 2 groups (data not shown).

Independent of the administration of NR, there was no difference in the incidence of cardiac events when cases were classified by the presence or absence of hypertension, diabetes, hypercholesterolemia, smoking at the time of the MI or the administration of $\beta$-blockers, and, in the case of males aged over 55 years, by the left ventricular ejection fraction, Killip classification, the infarct-related coronary artery, or the number of diseased vessels.

\section{Discussion}

Although the present study was retrospective, it found that the administration of NR did not cause an increase in cardiac events; in fact, in patients aged less than 55 years and in non-smokers it may even suppress the development of cardiac events.

Compared with Western patients, there is more involvement of coronary vasospasm in the development of MI in Japanese patients, ${ }^{8-10}$ and therefore the potential of CCBs to suppress coronary vasospasm ${ }^{19}$ may prevent both myocardial ischemia and the development of cardiac events in Japanese post-MI patients. The reason why NR was particularly effective in suppressing cardiac events in cases under 55 years of age was thought to be as follows. Vasospastic angina pectoris occurs most frequently in the 40-50 years age bracket in Japan and compared with reports in the West, fewer coronary vessels are usually involved in cases of vasospastic angina pectoris in Japan.$^{20}$ The present study also found that significantly fewer coronary vessels were involved in cases under 55 years of age than in the over-55 age bracket (data not shown). As demonstrated by subgroup analysis, there was a $6.0 \%$ incidence of cardiac events involving only 1 coronary artery in the NR group, which was half the incidence of $11.9 \%$ in the non-CCB group. However, when 2 or 3 coronary arteries were involved, the respective incidences were $17.7 \%$ and $20.2 \%$, so the efficacy of NR appeared to be decreased in multivessel disease.

Thus we consider that because coronary vasospasm is frequently involved in the cardiac events that occur in the relatively young cases aged less than 55 years, CCBs, which effectively prevent coronary vasospasm, could potentially prevent the development of cardiac events in this age bracket.

In the non-smokers NR significantly suppressed the development of cardiac events and that result was not demonstrated in the cases of continued smoking. The plasma concentration of nifedipine measured in smokers is significantly lower than that in non-smokers?22,23 Smoking is an important risk factor for coronary vasospasm; ${ }^{21}$ continued smoking may increasingly damage the function of the vascular endothelium and thus weaken the suppressive action of CCBs 22 Nakashima et al reported that NR suppresses the action of thromboxane $\mathrm{B}_{2}$ and 6-ketoprostaglandin $\mathrm{Fa}$, both platelet activation factors that act as triggers for coronary arterial thrombosis, which in turn causes acute coronary syndromes; however, in smokers this mechanism was reversed ${ }^{23}$

The main mechanism of the prevention of heart failure by CCBs is reducing the afterload by strong vasodilation, 24 thus reducing the burden on the heart, similar to the action of other vasodilators. Recently, the results of a meta-analy- sis of the effects of second-generation dihydropyridone CCBs on heart failure identified effects that may play a role in prevention of heart failure: an increase in left ventricular ejection fraction as a cardiac index; a decrease in isovolume relaxation time and an increase in early peak velocity as indexes of left ventricular diastolic dysfunction; and a decrease in the blood concentrations of norepinephrine ${ }^{25}$ The effect of CCBs on the prevention of left ventricular remodeling has also been reported? 26,27

Nifedipine causes an increase in nitric oxide ${ }^{26}$ which is produced when the vascular endothelium function improves, and has an antiproliferative action on vascular smooth muscles ${ }^{28}$ Therefore it suppresses the progression of atherosclerosis ${ }^{29,30}$ and may be able to prevent cardiac events.

The reason why it had been thought that short-acting CCBs were not only ineffective in preventing secondary MI, but even harmful, must be seen within the context of an era when reperfusion therapy had not been perfected, and most targeted cases probably had persistent stenosis and decreased cardiac function.-3 It should also be noted that target patients in the present study had been treated with a sustained-release preparation of nifedipine and the blood concentration curves showed a more gradual concentration gradient than do the curves found with short-acting preparations. The effect on the sympathetic nervous system was therefore relatively subdued, with less increase in heart rate $^{31}$ and a reduced burden on the heart.

In recent years there have been reports in Japan of the efficacy of long-acting $\mathrm{CCBs}, 32,33$ and those with a strongly antihypertensive action, excluding the short-acting ones ${ }^{5}$ that cause a dose-dependent increase in cardiac events, together with their activities other than the antihypertensive effect (ie, suppression of coronary vasospasm, improvement in endothelial function, anti-arteriosclerotic action etc), are considered to be effective in the prevention of cardiac events in Japanese. According to the WHO/ISH meta-analysis, ${ }^{34} \mathrm{CCBs}$ showed superior suppressive action on cerebrovascular accidents than other vasopressors, and they may be particularly effective in the treatment of the cases with IHD in Japan that are complicated by hypertension in which the incidence of cerebrovascular accidents is particularly high.

This report is the first in Japan to investigate the effect of CCBs on the prevention of secondary MI over a long period, and even though there has been a change to thirdgeneration CCBs that are taken once daily, these results are still evidence of the effect of pharmacotherapy on the prevention of secondary MI in Japanese patients.

\section{Study Limitations and Research in Progress}

Because this research was not based on prospective random assessment, subclass analysis was performed and corrections were made for patient background factors, but we cannot deny that there may have been some degree of bias. Other than patients in whom thrombolysis was contraindicated, those in whom a long time had elapsed since the event and those with large infarction were not included. The patients had survived the acute phase of MI and were discharged from hospital, indicating that they had relatively good cardiac function and few complications. Because the subjects were limited to those in whom coronary reperfusion therapy was performed shortly after the event, it may not be possible to apply these results to all cases of MI. The administration of NR to patients who died during hospitalization was not investigated. Furthermore, the changes in 
coronary risk factors and improvement of reperfusion therapy and drugs because of the progress in therapeutic technology over the study period of 10 years were not investigated.

The additional use or change to other drugs for the secondary prevention of MI, such as aspirin $35 \beta$-blockers, 36 HMG-CoA reductase ${ }^{37}$ etc, was not investigated, and it cannot be denied that these factors might have played a role in the prevention of cardiac events. Therefore, we have begun a prospective investigation of the effect of drugs on the secondary prevention of MI.

\section{References}

1. The Israeli Sprint Study Group. Secondary Prevention Reinfarction Isreli Nifedipine Trial (SPRINT): A randomized intervention trial of nifedipine in patients with acute myocardial infarction. Eur Heart $J$ 1988; 9: 354-364.

2. Goldbourt U, Behar S, Reicher-Reiss H, Zion M, Mandelzweig L, Kaplinsky E. Early administration of nifedipine in suspected acute myocardial infarction: The Secondary Prevention Reinfarction Israel Nifedipine Trial 2 Study. Arch Intern Med 1993; 153: 345-353.

3. Ishikawa K, Nakai S, Takenaka T, Kanamasa K, Hama J, Ogawa I, et al. Short-acting nifedipine and diltiazem do not reduce the incidence of cardiac events in patients with healed myocardial infarction: Secondary Prevention Group. Circulation 1997; 95: 2368-2373.

4. Held PH, Yusuf S, Furberg CD. Calcium channel blockers in acute myocardial infarction and unstable angina: An overview. BMJ 1989; 299: $1187-1192$.

5. Hennekens CH, Albert CM, Godfried SL, Gaziano JM, Buring JE. Adjunctive drug therapy of acute myocardial infarction: Evidence from clinical trials. N Engl J Med 1996; 335: 1660-1667.

6. Furberg CD, Psaty BM, Meyer JV. Nifedipine: Dose-related increase in mortality in patients with coronary heart disease. Circulation 1995; 92: 1326-1331.

7. Psaty BM, Furberg CD. Clinical implications of the World Health Organization-International Society of Hypertension statement on calcium antagonists. J Hypertens 1997; 15: 1197-1200.

8. Pristipino C, Beltrame JF, Finocchiaro ML, Hattori R, Fujita M, Mongiardo R, et al. Major racial differences in coronary constrictor response between japanese and caucasians with recent myocardial infarction. Circulation 2000; 101: 1102-1108.

9. Beltrame JF, Sasayama S, Maseri A. Racial heterogeneity in coronary artery vasomotor reactivity: Differences between Japanese and Caucasian patients. J Am Coll Cardiol 1999; 33: 1442-1452.

10. Akiyama H, Ishikawa K, Kanamasa K, Ogawa I, Koka H, Kamata N, et al. Increased coronary vasomotor tone in acute myocardial infarction patients with spontaneous coronary recanalization. Jpn Circ J 1997; 61: 503-509.

11. Ikegawa T, Chino M, Usuba F, Nishikawa K, Nakamura Y. Coronary angiography after myocardial infarction. A comparison between a Japanese community hospital and Western countries. Jpn Heart J 1986; 27: 279-285.

12. Hughes LO, Raval U, Raftery EB. First myocardial infarctions in Asian and white men. BMJ 1989; 298: 1345-1350.

13. Saito M, Fukami K, Hiramori K, Haze K, Sumiyoshi T, Kasagi H, et al. Long-term prognosis of patients with acute myocardial infarction: Is mortality and morbidity as low as the incidence of ischemic heart disease in Japan. Am Heart J 1987; 113: 891-897.

14. Kleinbloesem $\mathrm{CH}$, van Brummelen P, van de Linde JA, Voogd PJ, Breimer DD. Nifedipine: Kinetics and dynamics in healthy subjects. Clin Pharmacol Ther 1984; 35: 742-749.

15. Hagiwara T, Mikami T, Tabuchi Y, Kumahara Y. Pharmacokinetic of BAY a 1040 (nifedipine) $20 \mathrm{mg}$ tablet for 15 days administration in healthy male volunteers. Jpn Pharmacol Ther 1985; 13: 4481 (in Japanese).

16. The TIMI study group. The Thrombolysis in Myocardial Infarction (TIMI) trial. N Engl J Med 1985; 312: 932-936.

17. Myerburg RJ, Castellanos A. Cardiac arrest and sudden cardiac death. In: Braunwald E, editor. Heart disease: A text book of cardiovascular medicine. Philadelphia: WB Saunders; 1992; 756-789.

18. Ishikawa K, Miyataka M, Kanamasa K, Hayashi T, Takenaka T, Inoki $\mathrm{T}$, et al. Retrospective analysis showing less cardiac events in post-myocardial infarction patients treated with metoprolol: Secondary Prevention Group. Jpn Circ J 2000; 64: 358-364.

19. Yasue H, Nagao M, Omote S, Takizawa A, Miwa K, Tanaka S.
Coronary arterial spasm and Prinzmetal's variant form of angina induced by hyperventilation and Tris-buffer infusion. Circulation 1978; 58: 56-62.

20. Shimokawa H, Nagasawa K, Irie T, Egashira S, Egashira K, Sagara $\mathrm{T}$, et al. Clinical characteristics and long-term prognosis of patients with variant angina: A comparative study between western and Japanese populations. Int J Cardiol 1988; 18: 331-349.

21. Sugiishi M, Takatsu F. Cigarette smoking is a major risk factor for coronary spasm. Circulation 1993; 87: 76-79.

22. Deanfield J, Wright C, Krikler S, Ribeiro P, Fox K. Cigarette smoking and the treatment of angina with propranolol, atenolol, and nifedipine. N Engl J Med 1984; 310: 951-954.

23. Nakashima Y, Kawashima T, Nandate H, Yashiro A, Kuroiwa A. Sustained-release nifedipine (nifedipine-L) suppresses plasma thromboxane $\mathrm{B} 2$ and 6-keto prostaglandin $\mathrm{F} 1$ alpha in both young male smokers and nonsmokers. Am Heart J 1990; 119: 1267-1273.

24. Cody RJ. The hemodynamics of calcium-channel antagonists in hypertension: Vascular and myocardial responses. Circulation 1987; 75: $1175-1179$.

25. Cleophas TJ, van Marum R. Meta-analysis of efficacy and safety of second-generation dihydropyridine calcium channel blockers in heart failure. Am J Cardiol 2001; 87: 487-490.

26. Berkels R, Egink G, Marsen TA, Bartels H, Roesen R, Klaus W. Nifedipine increases endothelial nitric oxide bioavailability by antioxidative mechanisms. Hypertension 2001; 37: 240-245.

27. Schulman DS, Flores AR, Tugoen J, Dianzumba S, Reichek N. Antihypertensive treatment in hypertensive patients with normal left ventricular mass is associated with left ventricular remodeling and improved diastolic function. Am J Cardiol 1996; 78: 56-60.

28. Hirata A, Igarashi M, Yamaguchi H, Suwabe A, Daimon M, Kato T, et al. Nifedipine suppresses neointimal thickening by its inhibitory effect on vascular smooth muscle cell growth via a MEK-ERK pathway coupling with Pyk2. Br J Pharmacol 2000; 131: 1521-1530.

29. Lichtlen PR, Hugenholtz PG, Rafflenbeul W, Hecker H, Jost S, Deckers JW. Retardation of angiographic progression of coronary artery disease by nifedipine: Results of the International Nifedipine Trial on Antiatherosclerotic Therapy (INTACT). INTACT Group Investigators. Lancet 1990; 335: 1109-1113.

30. Waters D, Lesperance J, Francetich M, Causey D, Theroux P, Chiang YK, et al. A controlled clinical trial to assess the effect of a calcium channel blocker on the progression of coronary atherosclerosis. Circulation 1990; 82: 1940-1953.

31. Kleinbloesem CH, Van Brummelen P, Van de Linde JA, Voogd PJ, Breimer DD. Nifedipine: Kinetics and dynamics in healty subjects. Clin Pharmacol Ther 1984; 6: 742-749.

32. Yui Y, Sumiyoshi T, Kodama K, Hirayama A, Nonogi H, Kanmatsuse $\mathrm{K}$, et al. Japan Multicenter Investigation for Cardiovascular DiseasesB Study Group: Comparison of nifedipine retard with angiotensin converting enzyme inhibitors in Japanese hypertensive patients with coronary artery disease: The Japan Multicenter Investigation for Cardiovascular Diseases-B (JMIC-B) randomized trial. Hypertens Res 2004; 27: 181-191.

33. Japanese Beta-Blockers and Calcium Antagonists Myocardial Infarction (JBCMI) Investigators. Comparison of the effects of beta blockers and calcium antagonists on cardiovascular events after acute myocardial infarction in Japanese subjects. Am J Cardiol 2004; 93: 969-973.

34. Pahor M, Psaty BM, Alderman MH, Applegate WB, Williamson JD, Cavazzini C, et al. Health outcomes associated with calcium antagonists compared with other first-line antihypertensive therapies: A meta-analysis of randomised controlled trials. Lancet 2000; 356: 1949-1954.

35. Baigent C, Collins R, Appleby P, Parish S, Sleight P, Peto R. ISIS-2: 10 year survival among patients with suspected acute myocardial infarction in randomised comparison of intravenous streptokinase, oral aspirin, both, or neither (The ISIS-2 (Second International Study of Infarct Survival) Collaborative Group). BMJ 1998; 316: $1337-$ 1343.

36. Ishikawa K, Miyataka M, Kimura A, Takeda N, Hirano Y, Hayashi $\mathrm{T}$, et al. Secondary Prevention Group: Beta-blockers prevent cardiac events in Japanese patients with myocardial infarction. Circ J 2004; 68: $59-67$.

37. Matsuzaki M, Kita T, Mabuchi H, Matsuzawa Y, Nakaya N, Oikawa S, et al J-LIT Study Group. Japan Lipid Intervention Trial: Large scale cohort study of the relationship between serum cholesterol concentration and coronary events with low-dose simvastatin therapy in Japanese patients with hypercholesterolemia. Circ J 2002; 66: 1087-1095. 